\title{
Tailoring chemical and physical properties of fibrous scaffolds from block copolyesters containing ether and thio-ether linkages for skeletal differentiation of human mesenchymal stromal cells
}

Citation for published version (APA):

Chen, H., Gigli, M., Gualandi, C., Truckenmuller, R., van Blitterswijk, C., Lotti, N., Munari, A., Focarete, M. L., \& Moroni, L. (2016). Tailoring chemical and physical properties of fibrous scaffolds from block copolyesters containing ether and thio-ether linkages for skeletal differentiation of human mesenchymal stromal cells. Biomaterials, 76, 261-272. https://doi.org/10.1016/j.biomaterials.2015.10.071

Document status and date:

Published: 01/01/2016

DOI:

10.1016/j.biomaterials.2015.10.071

Document Version:

Publisher's PDF, also known as Version of record

Document license:

Taverne

Please check the document version of this publication:

- A submitted manuscript is the version of the article upon submission and before peer-review. There can be important differences between the submitted version and the official published version of record. People interested in the research are advised to contact the author for the final version of the publication, or visit the DOI to the publisher's website.

- The final author version and the galley proof are versions of the publication after peer review.

- The final published version features the final layout of the paper including the volume, issue and page numbers.

Link to publication

\footnotetext{
General rights rights.

- You may freely distribute the URL identifying the publication in the public portal. please follow below link for the End User Agreement:

www.umlib.nl/taverne-license

Take down policy

If you believe that this document breaches copyright please contact us at:

repository@maastrichtuniversity.nl

providing details and we will investigate your claim.
}

Copyright and moral rights for the publications made accessible in the public portal are retained by the authors and/or other copyright owners and it is a condition of accessing publications that users recognise and abide by the legal requirements associated with these

- Users may download and print one copy of any publication from the public portal for the purpose of private study or research.

- You may not further distribute the material or use it for any profit-making activity or commercial gain

If the publication is distributed under the terms of Article 25fa of the Dutch Copyright Act, indicated by the "Taverne" license above,

Download date: 26 Apr. 2023 


\title{
Tailoring chemical and physical properties of fibrous scaffolds from block copolyesters containing ether and thio-ether linkages for skeletal differentiation of human mesenchymal stromal cells
}

\author{
Honglin Chen ${ }^{\mathrm{a}, 1}$, Matteo Gigli ${ }^{\mathrm{b}, 1}$, Chiara Gualandi ${ }^{\mathrm{c}}$, Roman Truckenmüller ${ }^{\mathrm{a}}$, \\ Clemens van Blitterswijk ${ }^{a}$, Nadia Lotti ${ }^{b}$, Andrea Munari ${ }^{b}$, Maria Letizia Focarete ${ }^{c, d, * *}$, \\ Lorenzo Moroni a, * \\ a Department of Complex Tissue Regeneration, MERLN Institute for Technology Inspired Regenerative Medicine, 6200 MD Maastricht, The Netherlands \\ b Department of Civil, Chemical, Environmental and Materials Engineering, University of Bologna, 40131 Bologna, Italy \\ ' Department of Chemistry "G. Ciamician" and INSTM UdR of Bologna, University of Bologna, 40126 Bologna, Italy \\ ${ }^{\mathrm{d}}$ Health Sciences and Technologies - Interdepartmental Center for Industrial Research (HST-ICIR), University of Bologna, 40064, Ozzano dell'Emilia, \\ Bologna, Italy
}

\section{A R T I C L E I N F O}

\section{Article history:}

Received 29 August 2015

Received in revised form

22 October 2015

Accepted 26 October 2015

Available online 28 October 2015

\section{Keywords:}

Aliphatic copolyesters

Ether and thioether linkages

Electrospun scaffolds

Human mesenchymal stromal cells

Skeletal differentiation

\begin{abstract}
A B S T R A C T
Bioactive scaffolds for tissue engineering call for demands on new materials which can enhance traditional biocompatibility requirements previously considered for clinical implantation. The current commercially available thermoplastic materials, such as poly(lactic acid) (PLA), poly(glycolic acid) (PGA), poly $(\varepsilon$-caprolactone) (PCL) and their copolymers, have been used to fabricate scaffolds for regenerative medicine. However, these polymers have limitations including lacking of broadly tuning mechanical and degradable properties, and activation of specific cell-scaffold interactions, which limit their further application in tissue engineering. In the present study, electrospun scaffolds were successfully fabricated from a new class of block poly(butylene succinate)-based (PBS-based) copolyesters containing either butylene thiodiglycolate (BTDG) or butylene diglycolate (BDG) sequences. The polyesters displayed tunable mechanical properties and hydrolysis rate depending on the molecular architecture and on the kind of heteroatom introduced along the polymer backbone. To investigate their potential for skeletal regeneration, human mesenchymal stromal cells (hMSCs) were cultured on the scaffolds in basic, osteogenic and chondrogenic media. Our results demonstrated that PBS-based copolyesters containing thio-ether linkages (i.e. BTDG segments) were more favorable for chondrogenesis of hMSCs than those containing ether linkages (i.e. BDG sequences). In contrast, PBS-based copolyesters containing ether linkages showed enhanced mineralization. Therefore, these new functional scaffolds might hold potential for osteochondral tissue engineering applications.
\end{abstract}

(c) 2015 Elsevier Ltd. All rights reserved.

\section{Introduction}

A promising strategy for repairing damaged tissues and organs is to design scaffolds able to support and eventually control cell

\footnotetext{
* Corresponding author. Department of Complex Tissue Regeneration, MERLN Institute for Technology Inspired Regenerative Medicine, 6200 MD Maastricht, The Netherlands.

** Corresponding author. Department of Chemistry "G. Ciamician" and INSTM UdR of Bologna, University of Bologna, 40126 Bologna, Italy.

E-mail addresses: marialetizia.focarete@unibo.it (M.L. Focarete), I.moroni@ maastrichtuniversity.nl (L. Moroni)

${ }^{1}$ Equally contributing authors.
}

activity, i.e. adhesion, proliferation and differentiation. Electrospinning is a simple technique capable of producing non-woven scaffolds made of continuous fibers with diameters ranging from few tens of nanometers up to several micrometers [1]. The resulting fibrillary networks mimic the morphology of native extracellular matrix (ECM), which serves to organize cells and provides signals for cellular responses [2].

Among the manifold of current commercially available thermoplastic materials used to fabricate three-dimensional (3D) scaffolds for regenerative medicine, aliphatic polyesters undoubtedly represent so far the most extensive studied class, since they combine good physico-chemical and mechanical 
properties with assessed biocompatibility [3]. Poly(lactic acid) (PLA), poly(glycolic acid) (PGA), poly( $\varepsilon$-caprolactone) (PCL) and their copolymers are typically used [4] and their hydrolytic and enzymatic degradation under physiological conditions has been extensively proven [3]. Although these polymers have found many applications in clinical practice, the wide tuning of their mechanical, physico-chemical and biological properties is somehow limited [4]. For instance, the copolymerization of PLA with PCL enables to decrease polymer elastic modulus, thus obtaining more deformable materials that, however, are highly hydrophobic and display a very slow degradation rate. Hydrophilicity and hydrolysis rate can be significantly enhanced through copolymerization of PLA with PGA but, in this case, the rigidity of the material persists. This hampers the fabrication of 3D scaffolds capable of adapting to the needs of the specific tissue to be regenerated. Therefore, new polyesters with more flexibility in tuning their properties attract considerable attention in regenerative medicine.

In the last few years, an increasing number of researchers proposed poly(butylene succinate) (PBS) as a possible alternative to the above mentioned aliphatic polyesters due to the following advantages: (i) simple synthetic strategy through melt polycondensation; (ii) low cost of raw materials (1,4-butanediol and succinic acid), which can be also obtained from renewable resources [5]; (iii) high melting temperatures among poly(alkylene dicarboxylate)s $\left(\mathrm{T}_{\mathrm{m}}=113-115^{\circ} \mathrm{C}\right)$; (iv) good thermal stability (thus a wide processing temperature range); (v) proven biodegradability and biocompatibility [6]. Furthermore, PBS is already commercialized by different companies for various applications such as compost bags and mulching films, but also fishery, civil engineering and construction and for common household goods.

Many efforts have been recently devoted to target PBS modification aiming to achieve better performances with respect to the intended application. For biomedical applications, composites have been realized by incorporating organic or inorganic fillers such as chitosan, collagen, calcium phosphate or hydroxyapatite along the PBS macromolecular chain [6]. A plethora of PBS-based blends and copolymers have been also obtained [6]. Among other copolymerization techniques, reactive bending is a versatile and solvent free approach which permits to prepare block copolymers of different molecular architecture by simply varying the reaction time [7].

Recent studies have demonstrated that the properties of scaffold, such as scaffold elasticity, structure and organization, and chemistry, can direct stem cell differentiation into specific lineages [8-10]. In this study, electrospun scaffolds fabricated from a class of block PBS-based copolyesters containing either butylene thiodiglycolate (BTDG) or butylene diglycolate (BDG) sequences, obtained by reactive blending, are presented. In particular, the possibility to use the synthesized copolymers as an alternative to conventional polyesters was explored to achieve enhanced control over stem cell differentiation. In these systems, the addition of heteroatoms along the macromolecular chains has been demonstrated to tune chain flexibility, thus affecting polymer crystallinity and mechanical properties of aliphatic polyesters [11,12]. Moreover, through this strategy surface hydrophilicity has been modified, due to the presence of electronegative oxygen and sulphur atoms [13-15]. All these factors significantly impact the biodegradation rate and biocompatibility of the final materials $[16,17]$. Scaffolds with tailored chemical composition and physical properties have been prepared and characterized. Their hydrolytic degradation profile has been evaluated under physiological conditions. Finally, we show that these copolymers may have the potential to steer stem cell differentiation towards skeletal lineages.

\section{Materials and methods}

\subsection{Materials}

Dimethylsuccinate (DMS), 1,4-butanediol (BD), diglycolic acid (DGA), thiodiglycolic acid (TDGA), and titanium tetrabutoxide (TBT) (Sigma-Aldrich) were reagent grade products. All the reagents were used as supplied with the exception of TBT which was distilled before use. Chloroform, dichloromethane (DCM), 2chloroethanol (CE) and hexafluoro-2-propanol (HFIP) were purchased from Sigma-Aldrich and were used without any further purification.

\subsection{Polymer synthesis}

Starting homopolymers, i.e. PBS, poly(butylene diglycolate) (PBDG) and poly(butylene thiodiglycolate) (PBTDG) were synthesized in bulk by the usual two steps melt polycondensation, starting from 1,4-butanediol (BD) and DMS, DGA or TDGA, as reported elsewhere [11,12]. Two blends, PBS/PBDG and PBS/PBTDG, were obtained by melt mixing for 10 min equimolar amounts of PBS with PBDG and PBTDG, respectively, according to the procedures previously described [11,12]. Poly(butylene succinate/diglycolate) $\left(\mathrm{P}\left(\mathrm{BS}_{11} \mathrm{BDG}_{11}\right)\right)$ and poly(butylene succinate/thiodiglycolate) $\left(\mathrm{P}\left(\mathrm{BS}_{10} \mathrm{BTDG}_{10}\right)\right)$ copolyesters were obtained by melt mixing equimolar amounts of PBS with either PBDG (for 30 min) or PBTDG (for $45 \mathrm{~min})$, respectively $[11,12]$. The reactions were carried out at $225{ }^{\circ} \mathrm{C}$, under dry nitrogen atmosphere to prevent polymer degradation. Copolymer formation was catalysed by the residual titanium tetrabutoxide used for the synthesis of the parent homopolymers. The reactive blending provided two block copolymers $\left(\mathrm{P}\left(\mathrm{BS}_{11} \mathrm{BDG}_{11}\right)\right.$ and $\left.\mathrm{P}\left(\mathrm{BS}_{10} \mathrm{BTDG}_{10}\right)\right)$ with similar block length.

\subsection{Scaffold and film preparation}

PBS, PBS/PBDG and PBS/PBTDG blends, and $\mathrm{P}\left(\mathrm{BS}_{11} \mathrm{BDG}_{11}\right)$ and $\mathrm{P}\left(\mathrm{BS}_{10} \mathrm{BTDG}_{10}\right)$ copolymers were subjected to electrospinning to obtain 3D mats. Scaffolds were produced by using a customized electrospinning apparatus, comprised of a high-voltage power supply (SL 50 P 10/CE/230; Spellman), a syringe pump (KD Scientific 200 series), a glass syringe, a stainless steel blunt-ended needle (inner diameter $=0.84 \mathrm{~mm}$ ) connected with the power supply electrode, and a grounded aluminium plate-type collector $(7 \mathrm{~cm} \times 7 \mathrm{~cm})$. Polymer solution was dispensed through a Teflon tube to the needle which was placed vertically on the collecting plate at a measured distance (D). The scaffolds were produced at room temperature (RT) and a relative humidity of $40 \pm 5 \%$. The electrospun solution and the operating conditions for each polymer were selected after optimization experiments aimed at obtaining bead-free fibers and are reported in Table S1. Electrospun mats were kept under vacuum over $\mathrm{P}_{2} \mathrm{O}_{5}$ at RT overnight to remove residual solvents.

Films ( $0.2 \mathrm{~mm}$ thick) of PBS, blends and copolymers were obtained by compression moulding the polymers between Teflon plates, with an appropriate spacer, at $140{ }^{\circ} \mathrm{C}$ for $1 \mathrm{~min}$ under a pressure of 2 ton $\mathrm{m}^{-2}$ (Carver C12, laboratory press).

\subsection{Material characterization}

Polymer structure and composition were determined by means of proton nuclear magnetic resonance $\left({ }^{1} \mathrm{H}\right.$ NMR) spectroscopy, whereas the distribution of the co-monomeric sequences along the polymer chain was evaluated by ${ }^{13} \mathrm{C}$ NMR spectroscopy. The measurements were carried out at RT by employing a Varian Inova 400MHz instrument (Agilent Technologies, USA). Molecular weights 
were evaluated by gel permeation chromatography (GPC) at $30^{\circ} \mathrm{C}$ using a 1100 HPLC system (Agilent Technologies, USA) equipped with PLgel 5- $\mu \mathrm{m}$ MiniMIX-C column (Agilent Technologies, USA). A refractive index was employed as detector. Chloroform was used as eluent with a $0.3 \mathrm{~mL} / \mathrm{min}$ flow and sample concentrations of about $2 \mathrm{mg} / \mathrm{mL}$. A molecular weight calibration curve was obtained with polystyrene standards in the range of molecular weight 2000-100,000 g/mol. Thermogravimetric analysis (TGA) was carried out under nitrogen atmosphere using a Perkin Elmer TGA7 apparatus (gas flow: $30 \mathrm{~mL} / \mathrm{min}$ ) at $10{ }^{\circ} \mathrm{C} / \mathrm{min}$ heating rate, up to $900{ }^{\circ} \mathrm{C}$. Calorimetric measurements were conducted by using a Perkin Elmer DSC7 instrument. In the typical setup, the external block temperature control was set at $-120^{\circ} \mathrm{C}$ and weighed samples of c.a. $10 \mathrm{mg}$ were heated up to $40^{\circ} \mathrm{C}$ above fusion temperature at a rate of $20^{\circ} \mathrm{C} / \mathrm{min}$. Scanning electron microscopic (SEM) observations were carried out using a Philips 515 SEM (FEI, Eindhoven, The Netherlands) at an accelerating voltage of $15 \mathrm{kV}$, on samples sputter coated with gold. The distribution of fibre diameters was determined through the measurement of approximately 150 fibres by means of an acquisition and image analysis software (EDAX Genesis, New York, USA), and the results were given as the average diameter \pm standard deviation. Static contact angle measurements were performed on polymer films using a KSV CAM101 (KSV, Espoo, Finland) instrument at ambient conditions, by recording the side profiles of deionized water drops for image analysis. Five drops were observed on different areas for each film, and contact angles were reported as the average value \pm standard deviation. Stressstrain measurements were performed with an Instron 4465 tensile testing machine equipped with a $100 \mathrm{~N}$ load cell on rectangular films, according to ASTM D882-02 standard. Sample were $5 \mathrm{~mm}$ wide, the gauge length was $20 \mathrm{~mm}$ and the cross-head speed was $5 \mathrm{~mm} / \mathrm{min}$. Load-displacement curves were obtained and converted to stress-strain curves. At least six replicate specimens were run for each sample and results were provided as the average value \pm standard deviation.

\subsection{Hydrolytic degradation studies}

Hydrolytic degradation studies were carried out on rectangular mats of PBS, blends and copolymers in triplicate. Prior to degradation experiments, each specimen was dried over $\mathrm{P}_{2} \mathrm{O}_{5}$ under vacuum at RT, and weighed to obtain the sample initial mass. Mats were individually immersed in phosphate buffered solution $(0.1 \mathrm{M}$, $\mathrm{pH}=7.4$ ) and incubated in a SW22 Julabo shaking water bath at $37^{\circ} \mathrm{C}$ and $50 \mathrm{rpm}$. The buffer solution was periodically changed to keep the $\mathrm{pH}$ constant during the entire time scale of the degradation experiments. At different time intervals, triplicate specimens for each sample were recovered from the bath, repeatedly washed with deionized water and dried over $\mathrm{P}_{2} \mathrm{O}_{5}$ under vacuum to constant weight. The mass loss was determined gravimetrically by comparing the dry weight remaining at a specific time with the initial sample weight. The molecular weight of each recovered sample was determined by GPC. ${ }^{1} \mathrm{H}$ NMR analysis was performed to detect changes in the molecular composition during the hydrolysis experiments and differential scanning calorimetry (DSC) was used to evaluate the change in crystallinity degree.

\subsection{Cell culture and seeding}

Human mesenchymal stromal cells (hMSCs, donor No. 8001 L) were provided from Texas A\&M Health Science Center, which has supplied standardized preparations of MSCs to hundreds of laboratories under the auspices of an NIH/NCRR grant (P40 RR 17447-06). Briefly, human bone marrow aspirates were obtained under a protocol approved by an institutional review board.
Mononuclear cells were separated from bone marrow aspirate using density centrifugation. They were plated to achieve adherent hMSCs and harvested when cells reached $60-80 \%$ confluence. These cells were called passage zero (P0) cells and were further expanded, harvested and frozen at passage one (P1). Prior to release, the frozen P1 cells were analyzed over three passages to assess successful expression of MSCs surface markers [18,19]. To achieve sufficient cells for seeding onto scaffolds, P1 cells were expanded in proliferation medium (PM), consisting of $\alpha$-MEM (Gibco), 10\% fetal bovine serum (Lonza), 2 mM L-glutamine (Gibco), $0.2 \mathrm{mM}$ ascorbic acid (Sigma-Aldrich), $100 \mathrm{U} / \mathrm{mL}$ penicillin and $100 \mathrm{mg} / \mathrm{mL}$ streptomycin (Gibco) and $1 \mathrm{ng} / \mathrm{mL}$ recombinant basic fibroblast growth factor (bFGF, Instruchemie). Cells were harvested for further sub-cultures when they became $80-90 \%$ confluence. Electrospun scaffolds were placed in cell culture plates and pressed with rubber O-rings (Eriks BB, The Netherlands) to prevent them from floating. The specimens were sterilized by immersion in $70 \%$ $(\mathrm{v} / \mathrm{v})$ ethanol for $15 \mathrm{~min}$ for three times. Subsequently, scaffolds were washed for 1 min with PBS for three times and immersed in basic medium (BM) overnight before cell seeding. A density of $5 \times 10^{3}$ cells $/ \mathrm{cm}^{2}$ was used to seed hMSCs onto electrospun scaffolds. Cell-scaffold constructs were cultured for up to 28 days in BM consisting of PM without bFGF, osteogenic medium (OM) comprising BM supplemented with $1 \times 10^{-6} \mathrm{M}$ dexamethasone, mineralization medium (MM) composed of OM plus $\beta$-glycerol phosphate, and chondrogenic medium (CM) containing DMEM (Gibco) supplemented with 1\% ITS premix (Micronic BV), $50 \mu \mathrm{g} / \mathrm{mL}$ ascorbic acid (Sigma-Aldrich), 100 units/mL penicillin (Life technologies), $100 \mu \mathrm{g} / \mathrm{mL}$ streptomycin (Life technologies), $100 \mathrm{nM}$ dexamethasone (Sigma-Aldrich), $40 \mu \mathrm{g} / \mathrm{mL}$ proline (Sigma-Aldrich), $100 \mu \mathrm{g} / \mathrm{mL}$ sodium pyruvate (Life technologies), $0.01 \mu \mathrm{g} /$ mL TGF $\beta 1$ (R\&D systems). Culture experiments were performed in an incubator with $5 \% \mathrm{CO}_{2}$ humid atmosphere at $37^{\circ} \mathrm{C}$. Culture medium was refreshed every 2 days.

\subsection{Metabolic activity}

Cell culture medium was removed from cell-scaffold constructs and supplemented with a medium containing $10 \%(\mathrm{v} / \mathrm{v})$ Presto Blue $^{\mathrm{TM}}$ reagent (Life technologies). The cell-scaffold constructs were incubated at $37^{\circ} \mathrm{C}$ for $1 \mathrm{~h}$ in the dark. Fluorescence was measured at $590 \mathrm{~nm}$ using a multi-label plate reader (Perkin Elmer Victor3 1420, USA).

\subsection{Cell morphology analysis}

Cell morphology and attachment on scaffolds was determined by SEM using an XL 30 ESEM-FEG (Philips, The Netherlands). Briefly, samples were rinsed twice with PBS, fixed with $10 \%$ formalin for $2 \mathrm{~h}$. After washing with PBS two times, the samples were dehydrated with a gradient ethanol series, dried by using critical point drying (Balzers CPD 030) and sputtered with gold (Cressington) before SEM analysis.

\subsection{Quantification of DNA}

Samples were washed with PBS three times and stored at $-80^{\circ} \mathrm{C}$ overnight. After thawing, samples were lysated for $16 \mathrm{~h}$ with a Tris/ EDTA buffer containing $1 \mathrm{mg} / \mathrm{mL}$ proteinase $\mathrm{K}, 185 \mu \mathrm{g} / \mathrm{mL}$ iodoacetamine (Sigma-Aldrich) and $10 \mu \mathrm{g} / \mathrm{mL}$ Pepstatin A (Sigma-Aldrich). Subsequently, the quantification of the total amount of DNA was examined by using the CyQuant ${ }^{\circledR}$ DNA assay (Molecular Probes, Eugene, USA) as previously reported [20]. Lysate was pipetted in duplicate to a black 96-well plate, followed by addition of NaCl-EDTA buffer containing component B of the kit $(20 \times)$ and 
RNase $(1000 \times)$. The plate was incubated for $1 \mathrm{~h}$ at RT. Subsequently, Gr-dye solution was added and the samples were incubated for $15 \mathrm{~min}$. The fluorescence signal was determined using a spectrophotometer (Victor3 1420, Perkin Elmer, USA) at an excitation wavelength of $480 \mathrm{~nm}$ and emission wavelength of $520 \mathrm{~nm}$.

\subsection{Alkaline phosphatase activity (ALP) assay}

The protocol for measuring ALP activity was similar to a previous study [21]. Briefly, the cell-scaffold constructs were digested for $1 \mathrm{~h}$ at RT in a cell lysis buffer at a pH 7.8 composed of $0.1 \mathrm{M} \mathrm{KH}_{2} \mathrm{PO}_{4}$, $0.1 \mathrm{M} \mathrm{K}_{2} \mathrm{HPO}_{4}$ and $0.1 \%$ Triton X-100. Then, cell lysates were pipetted in duplicate to 96-well plate. After addition of CDP-star ${ }^{\circledR}$ (Roche Life Science), the lysate were incubated for $15 \mathrm{~min}$ at RT. The measurements were performed on a Victor3 1420 (Perkin Elmer, USA) plate reader. The value of ALP activity was normalized to DNA quantity per scaffold.

\subsection{Glycosaminoglycan (GAG) assay}

Cell-scaffold constructs were washed with PBS three times and stored at $-80^{\circ} \mathrm{C}$ for at least $24 \mathrm{~h}$. After thawing, the constructs were digested for $16 \mathrm{~h}$ with Tris/EDTA buffer as mentioned above. The amount of GAG was determined spectrophotometrically after reaction with $16 \mathrm{mg}$ of dimethylmethylene blue dye (DMMB, Sigma-Aldrich) in a $10 \mathrm{mM}$ hydrochloric acid solution containing $3.04 \mathrm{~g} / \mathrm{L}$ of glycine and $2.37 \mathrm{~g} / \mathrm{L}$ of $\mathrm{NaCl}$. The absorbance was measured on a micro plate reader (Multiskan GO, Thermo Fisher, USA). The amount of GAG was calculated using a standard of chondroitin sulfate (Sigma-Aldrich).

\subsection{Histological staining}

ALP staining was carried out by using an Alkaline phosphatase kit (Sigma-Aldrich). Samples were fixed in $40 \%$ citrate working solution in acetone for $30 \mathrm{~s}$ and rinsed with deionized water three times. Alkaline dye mixture was added and incubated for $30 \mathrm{~min}$ at RT in the dark. Samples were finally rinsed thoroughly with deionized water three times. For alizarin red staining (ARS) assay, after fixation in $10 \%$ formalin for $1 \mathrm{~h}$, samples were rinsed with PBS three times, washed twice with distilled water and stained with a freshly filtered $2 \%$ aqueous Alizarin red solution ( $\mathrm{pH} \mathrm{4.2)} \mathrm{for} 2$ min. The excess stain was washed off thoroughly with distilled water. To quantify the orange-red coloration of ARS, the protocol was performed as described in a previous study [22,23]. After removing excess water, samples were transferred to a microcentrifuge tube. A $10 \%$ acetic acid solution was added and incubated for $30 \mathrm{~min}$ at RT with shaking. The slurry was centrifuged for $15 \mathrm{~min}$ at $20,000 \mathrm{~g}$ after vortexing for $30 \mathrm{~s}$. Then, the supernatant was transferred to a new $1.5-\mathrm{mL}$ microcentrifuge tube. A $10 \%$ ammonium hydroxide was utilized to neutralize the acid. Aliquots of the supernatant were read in triplicate at $405 \mathrm{~nm}$ in 96-well format using opaque-walled, transparent-bottomed plates (Fisher Lifesciences). All the images for ALP staining and ARS staining were taken using a stereomicroscope (Nikon SMZ800 with Q-imaging Retiga 1300 camera).

\subsection{Quantitative PCR analysis}

To analyze the gene expression of hMSCs on scaffolds, total RNA was isolated using a combination of TRIzol $^{\circledR}$ with a NucleoSpinRNAII ISOLATON ${ }^{\circledR}$ kit (Bioke). Briefly, scaffolds at day 7 and day 28 were rinsed with PBS three times and $1 \mathrm{~mL}$ of TRIzol was added to each sample. After addition of chloroform, phase separation occurred by centrifugation at $12,000 \mathrm{~g}$. The aqueous phase containing RNA was collected, mixed with equal volume of $75 \%(v / v)$ ethanol and loaded onto an RNA binding column of the kit. After a series of purification steps, RNA was re-suspended in RNase-free water and collected using a clean Eppendorf ${ }^{B}$ tube by centrifugation at $12,000 \mathrm{~g}$. The concentration and purity of RNA were measured by using a spectrophotometer (ND 1000, Nanodrop Technologies, USA). iScript (Bio-Rad, Veenendaal, the Netherlands) was used for the cDNA synthesis following the manufacturer's instruction. Quantitative polymerase chain reaction (qPCR) was carried out using SYBR-green supermix (Bio-Rad). Cycling parameters for running qPCR were set as follows: initial denaturation at $95{ }^{\circ} \mathrm{C}$ for $10 \mathrm{~min}$, followed by 40 cycles of $15 \mathrm{~s}$ at $95^{\circ} \mathrm{C}$ and $1 \mathrm{~min}$ at $60^{\circ} \mathrm{C}$. The sequences of the analyzed primers are shown in Table S3. Data are expressed as fold change relative to controls, after normalizing to B2M.

\subsection{Statistical analysis}

All data points are expressed as mean \pm standard deviation. Statistical difference was determined by using two-way analysis of variance (ANOVA), followed by a Tukey's post-hoc test. A value of $\mathrm{p}<0.05$ was considered statistically significant.

\section{Results and discussion}

\subsection{Electrospinning and sample characterization}

PBS, PBDG and PBTDG displayed a similar chemical structure, all containing two ester groups per repeating unit along a saturated aliphatic chain (Fig. 1). With respect to PBS, differences can be observed in the acid sub-units: PBDG contains an ether bond while PBTDG a thio-ether bond. We previously demonstrated that these minimal differences in the polymer backbone have a remarkable effect on polymer thermo-mechanical properties [11,12]. In the present study, physical blends of PBS with PBDG and PBTDG and copolymers of PBS containing either BDG or BTDG units with long block length were considered for scaffold fabrication, since these polymeric systems possess physico-chemical and mechanical characteristics significantly different from each other and from the PBS homopolymer. The molecular characterization of the polymeric systems investigated in the present work is reported in Table 1.

Both the blends and the copolyesters are characterized by relatively high molecular weights. This result indicates that no relevant thermal degradation occurred during the reactive blending. Looking into more detail, a slight decrease of molecular weight can be observed for the block copolymers. This result has been previously described and can be explained on the basis of two opposite effects: chain scission and transesterification reactions $[11,12]$. For short mixing times, i.e. those here employed, the chain scission reactions prevailed over transesterifications and therefore a decrease of molecular weight could be detected.

The chemical structure and composition of all copolyesters, determined by ${ }^{1} \mathrm{H}$ NMR were found to be consistent with the expected ones. ${ }^{13} \mathrm{C}$ NMR measurements were performed to study the structural changes due to the reactive blending. As far as the two blends are concerned, the NMR spectrum is the simple addition of PBS and PBTDG ones, indicating that no appreciable chemical reactions took place during the mixing. On the contrary, in $\mathrm{P}\left(\mathrm{BS}_{10} \mathrm{BTDG}_{10}\right)$ and $\mathrm{P}\left(\mathrm{BS}_{11} \mathrm{BDG}_{11}\right)$ two new peaks developed in the region between 64.1 and $65.5 \mathrm{ppm}$ (where the signals due to the carbon atoms of the 1,4-butanediol glycol subunit are located), due to the BS-BTDG and BS-BDG mixed sequences, respectively [11,12]. Lastly, the average block length has been calculated from the equations previously reported [11,12].

Electrospinning conditions parameters were optimized in order to obtain defect-free fibres. The scaffolds were highly porous with 


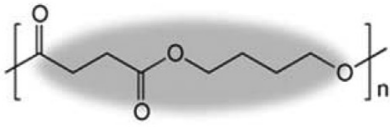

PBS

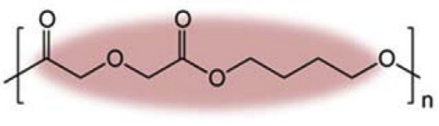

PBDG<smiles>C[In](C)COCCCCCOC(=O)CSCC(C)(C)C</smiles>

PBTDG<smiles></smiles>

$\mathrm{P}\left(\mathrm{BS}_{11} \mathrm{BDG}_{11}\right)$ $\mathrm{P}\left(\mathrm{BS}_{10} \mathrm{BTDG_{10 }}\right)$

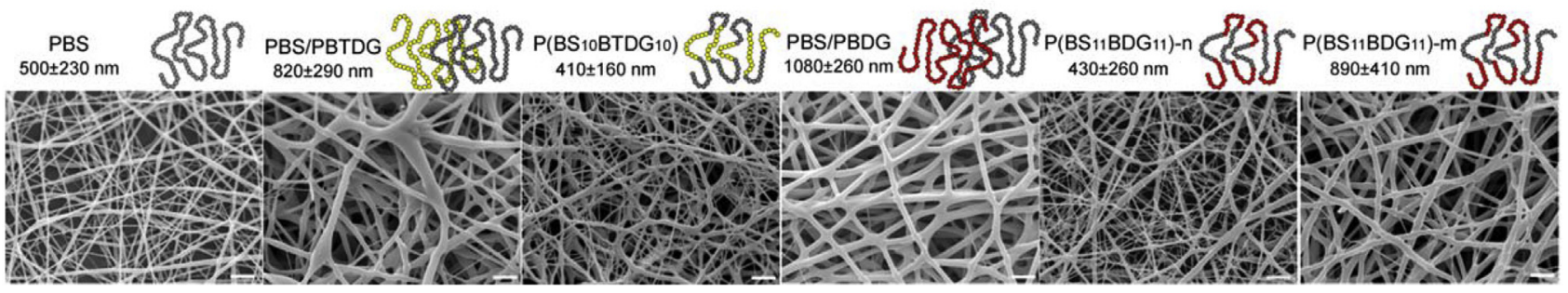

Fig. 1. Polymer chemical formulas, SEM micrographs and fibre dimensions of the obtained scaffolds.

Table 1

Polymer and scaffold characterization.

\begin{tabular}{|c|c|c|c|c|c|c|c|c|}
\hline Polymer & $\mathrm{M}_{\mathrm{n}}^{\mathrm{a}}(\mathrm{g} / \mathrm{mol})$ & $\mathrm{PDI}^{\mathrm{a}}$ & $\mathrm{T}_{\mathrm{g}}^{\mathrm{b}}\left({ }^{\circ} \mathrm{C}\right)$ & $\mathrm{T}_{\mathrm{m}, \mathrm{BDG}}{ }^{\mathrm{b}}\left({ }^{\circ} \mathrm{C}\right)$ & $\mathrm{T}_{\mathrm{m}}, \mathrm{BS}^{\mathrm{b}}\left({ }^{\circ} \mathrm{C}\right)$ & $\Delta \mathrm{H}_{\mathrm{m}}, \mathrm{BDG}^{\mathrm{b}}(\mathrm{J} / \mathrm{g})$ & $\Delta \mathrm{H}_{\mathrm{m}}, \mathrm{BS}^{\mathrm{b}}(\mathrm{J} / \mathrm{g})$ & $\mathrm{WCA}^{\mathrm{C}}\left({ }^{\circ}\right)$ \\
\hline PBS & 34,600 & 2.5 & -32 & 1 & 115 & 1 & 75 & $96 \pm 1$ \\
\hline PBS/PBTDG & 37,000 & 2.6 & -45 & i & 113 & i & 33 & $81 \pm 2$ \\
\hline $\mathrm{P}\left(\mathrm{BS}_{10} \mathrm{BTDG}_{10}\right)$ & 30,200 & 2.5 & -44 & i & 100 & i & 30 & $79 \pm 4$ \\
\hline PBS/PBDG & 23,600 & 2.8 & -29 & 63 & 114 & 28 & 34 & $72 \pm 2$ \\
\hline $\mathrm{P}\left(\mathrm{BS}_{11} \mathrm{BDG}_{11}\right)$ & 19,700 & 2.3 & -30 & 1 & 106 & 1 & 35 & $74 \pm 2$ \\
\hline
\end{tabular}

${ }^{a}$ By GPC performed on polymers in form of powder.

b By DSC performed on polymeric scaffolds.

c By WCA performed on polymers in form of film.

microscale interstitial pores made of randomly oriented fibres. In the case of $\mathrm{P}\left(\mathrm{BS}_{11} \mathrm{BDG}_{11}\right)$, two different polymeric solutions were prepared to obtain scaffolds with either micrometric or nanometric diameters (i.e. $890 \pm 410 \mathrm{~nm}$ and $410 \pm 160 \mathrm{~nm}$ ) that were labelled $\mathrm{P}\left(\mathrm{BS}_{11} \mathrm{BDG}_{11}\right)-\mathrm{m}$ and $\mathrm{P}\left(\mathrm{BS}_{11} \mathrm{BDG}_{11}\right)-\mathrm{n}$, respectively (Fig. 1 and Table S1).

Electrospun fibres were characterized by TGA and DSC. TGA did not reveal residual solvents in the fabricated fibres and confirmed that electrospinning process did not affect polymer thermal degradation behaviour. DSC was used to evaluate thermal transitions in the electrospun mats (Table 1). The calorimetric data of $\mathrm{P}\left(\mathrm{BS}_{11} \mathrm{BDG}_{11}\right)-\mathrm{m}$ and $\mathrm{P}\left(\mathrm{BS}_{11} \mathrm{BDG}_{11}\right)$-n were identical within the experimental errors. The phase behaviour of the polymers under investigation was similar. As far as the glass transition phenomenon is concerned, only one glass transition temperature $\left(\mathrm{T}_{\mathrm{g}}\right)$ was always clearly evident suggesting the presence of a homogeneous amorphous state. All polymers were semicrystalline, being the corresponding calorimetric traces (Fig. S1) characterized by a significant melting endotherm. The overall heat of fusion $\left(\Delta \mathrm{H}_{\mathrm{m}}\right)$ decreased from blends to block copolymers because of the reduced length of crystallisable sequences. The copolymer containing ether-oxygen showed a slightly bigger $\Delta \mathrm{H}_{\mathrm{m}}$ associated to the PBS crystal phase compared to the thio-ether containing copolymer. This implied that the PBS crystallization was less hampered in the copolymer containing BDG co-units. Interestingly, in the PBS/PBDG blend two distinct melting phenomena were evident, suggesting the simultaneous presence of the crystalline phases of the two homopolymers. This result has been previously confirmed by X-ray analyses
[12]. For the blends, the melting temperature $\left(T_{m}\right)$ was equal to that of PBS (and of PBDG homopolymer in the case of PBS/PBDG), while it decreased in the block copolymers because of the formation of a less perfect crystalline phase.

To investigate the effect of polymer chemistry on material hydrophilicity, water contact angle (WCA) measurements were performed on hot-pressed films and the results reported in Table 1. The significant decrease of WCA values in blends and copolymers was due to the introduction of highly electronegative atoms ( $O$ and $S$ ) along the PBS polymeric chain, which has the effect of increasing material surface wettability, as previously reported for other polymeric systems $[13-17,24]$. The polymers containing BDG repeating units displayed a lower WCA than those containing BTDG units. Thus, the former were more hydrophilic as a consequence of the higher electronegativity of oxygen atoms with respect to sulphur ones.

In order to correlate bulk mechanical properties with polymer chemical structure, tensile stress-strain measurements were carried out on polymeric films rather than electrospun fibers. Indeed, it is somewhat difficult to make a direct comparison among stressstrain data of non-woven electrospun fibrous matrices since it is already established that mechanical data depend not only on the type of polymeric material and on single fiber features, but also on the arrangement of the fibers in the nonwoven matrices, such as fiber direction in the mat, fiber curvature, fiber interconnections, fiber fusion at contact points and mat porosity [25,26]. Elastic modulus (E), stress at break $\left(\sigma_{\mathrm{b}}\right)$ and elongation at break $\left(\varepsilon_{\mathrm{b}}\right)$ of PBS, $\mathrm{PBS} / \mathrm{PBTDG}, \mathrm{P}\left(\mathrm{BS}_{10} \mathrm{BTDG}_{10}\right), \mathrm{PBS} / \mathrm{PBDG}$, and $\mathrm{P}\left(\mathrm{BS}_{11} \mathrm{BDG}_{11}\right)$ are 
reported in Fig. 2. Both the two blends and the copolymers were characterized by a lower elastic modulus than PBS and by a higher elongation at break (with the only exception of PBS/PBDG). Moreover, $\mathrm{E}$ and $\varepsilon_{\mathrm{b}}$ were respectively lower and higher in the case of block copolymers compared to the corresponding blends. This behaviour could be due to the decrease in the amount of hard crystal phase when comparing the blend with the corresponding copolymer (Table 1). The presence of thioether bonds along the polymer backbone caused an increase of the elongation at break and a decrease of the elastic modulus compared to the polymers containing ether linkages with the same molecular architecture. This result could be ascribed to the higher chain flexibility of BTDG units due to the presence along the polymeric chain of $\mathrm{C}-\mathrm{S}$ bonds longer than the $\mathrm{C}-\mathrm{O}$ ones and due to weaker interchain interactions because of the lower electronegativity of sulphur atoms compared to oxygen ones.
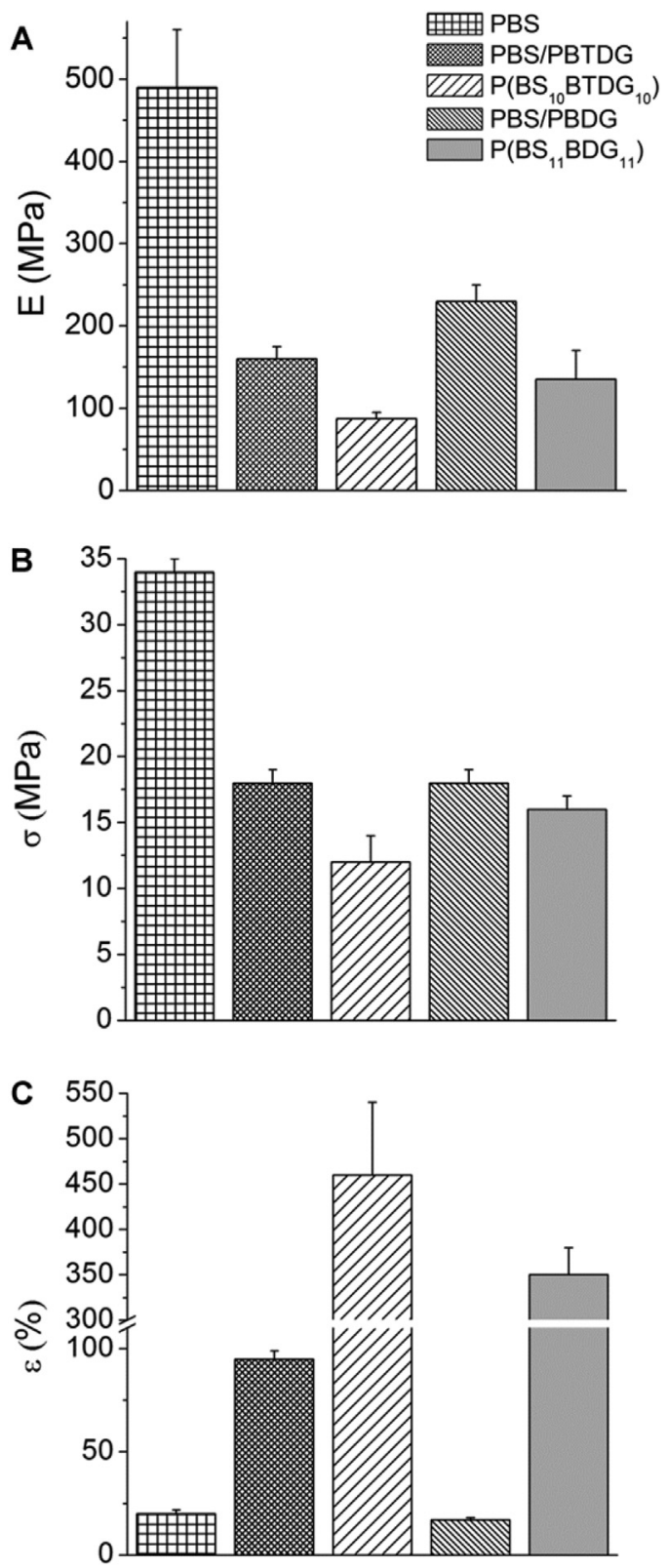

Fig. 2. (A) Elastic modulus $E$; (B) stress at break $\sigma_{\mathrm{b}}$ and (C) deformation at break $\varepsilon_{\mathrm{b}}$ of the polymers under investigation.

\subsection{Hydrolytic degradation}

Hydrolytic degradation experiments were performed under physiological conditions on the electrospun mats in order to evaluate the effect of the following factors on the hydrolysis rate: (i) introduction of hydrophilic BDG and BTDG co-units in the PBS macromolecular chain; (ii) type of heteroatom (O or S) introduced; (iii) different molecular architecture (blend or block copolymer). Hydrolytic degradation of these scaffolds can be interpreted on the basis of two different factors: crystallinity degree and surface hydrophilicity [27].

Comparable results were obtained for both $\mathrm{P}\left(\mathrm{BS}_{11} \mathrm{BDG}_{11}\right)-\mathrm{m}$ and $\mathrm{P}\left(\mathrm{BS}_{11} \mathrm{BDG}_{11}\right)-\mathrm{n}$ indicating that the fiber diameters considered in the present work did not affect degradation rate. Therefore, for this polymer, average results of the two mats were reported (Fig. 3). After 162 days of incubation, PBS practically did not lose weight whereas polymer blends and block copolymers appreciably degraded. In particular, ether-oxygen containing polyesters showed a higher degradation rate with respect to sulphur containing ones. Moreover, Fig. 3A shows that the weight loss of block copolymer is higher than the corresponding blend. The trend was particularly evident if we consider PBS/PBDG and $\mathrm{P}\left(\mathrm{BS}_{11} \mathrm{BDG}_{11}\right)$. On the contrary, only a small difference has been recorded in the case of PBS/ PBTDG and $\mathrm{P}\left(\mathrm{BS}_{10} \mathrm{BTDG}_{10}\right)$.

Overall, copolymers containing BDG sequences degraded faster than those containing BTDG ones because of the higher hydrophilicity of the former (Table 1). By comparing the blend with the corresponding copolymer, $\mathrm{P}\left(\mathrm{BS}_{11} \mathrm{BDG}_{11}\right)$ degraded to a higher extent than PBS/PBDG because of the lower crystallinity degree, while the two sulphur containing polymers underwent a similar degradation profile because of their comparable crystallinity degree and hydrophilicity (Table 1 ). The percentage of residual number average molecular weight for $\mathrm{PBS}, \mathrm{P}\left(\mathrm{BS}_{11} \mathrm{BDG}_{11}\right)$ and $P\left(B S_{10} B D_{D G}\right)\left(M_{n}\right.$ res\%) is reported in Fig. $3 B$ as a function of incubation time. The three samples underwent a decrease of $M_{n}$ with time, although PBS did not show any weight loss in the time range investigated (Fig. 3A). This is not surprising, taking into account that in the first stages of hydrolytic degradation a substantial decrease in molecular weight occurs even if weight losses are still negligible [28]. PBS decrease of $M_{n}$ was lower due to its high crystallinity degree, high crystal perfection and hydrophobicity, while in the case of copolymers the change of molecular weight was more evident and seemed to be affected by the type of polymer investigated: for $\mathrm{P}\left(\mathrm{BS}_{11} \mathrm{BDG}_{11}\right)$ the $\mathrm{M}_{\mathrm{n}}$ decrease was higher than that of $P\left(B S_{10} B T D G_{10}\right)$. The calculation of $M_{n}$ was not possible for the two blends, because the GPC traces of the analysed polymers revealed a shoulder since the very beginning of the incubation period that turned into two partially overlapped peaks. With increasing of the incubation time, a second peak was detectable (Fig. 3E). Therefore, to monitor the degradation process, the molecular weight of both peaks $\left(\mathrm{M}_{\mathrm{p}}, 1\right.$ and $\left.\mathrm{M}_{\mathrm{p}}, 2\right)$ was calculated (Table S2). For both blends the position of one peak slightly changed $\left(M_{p}, 2\right)$, while $M_{p}, 1$ remarkably decreased with the increase of incubation time. By considering the difference in repeating units hydrophilicity, we can reasonably assume that $\mathrm{M}_{\mathrm{p}}, 1$ is related to either PBDG or PBTDG macromolecular chains that underwent a substantial hydrolytic degradation, while $\mathrm{M}_{\mathrm{p}}, 2$ corresponds to PBS macromolecular chains, whose molecular weight decrease was significantly lower.

In order to gain a better understanding of the hydrolysis mechanism occurring in the polymers, ${ }^{1} \mathrm{H}$ NMR measurements were performed on degraded retrieved samples. Fig. $3 \mathrm{C}$ reports the content of BS units in mol\%, at a certain time of degradation, normalized to the initial $\mathrm{mol} \% \mathrm{BS}\left(\mathrm{mol}_{\mathrm{BSS}} / \mathrm{mol}_{\mathrm{BSS}}\right)$ as a function of degradation time. In all samples, an evident increase of BS 

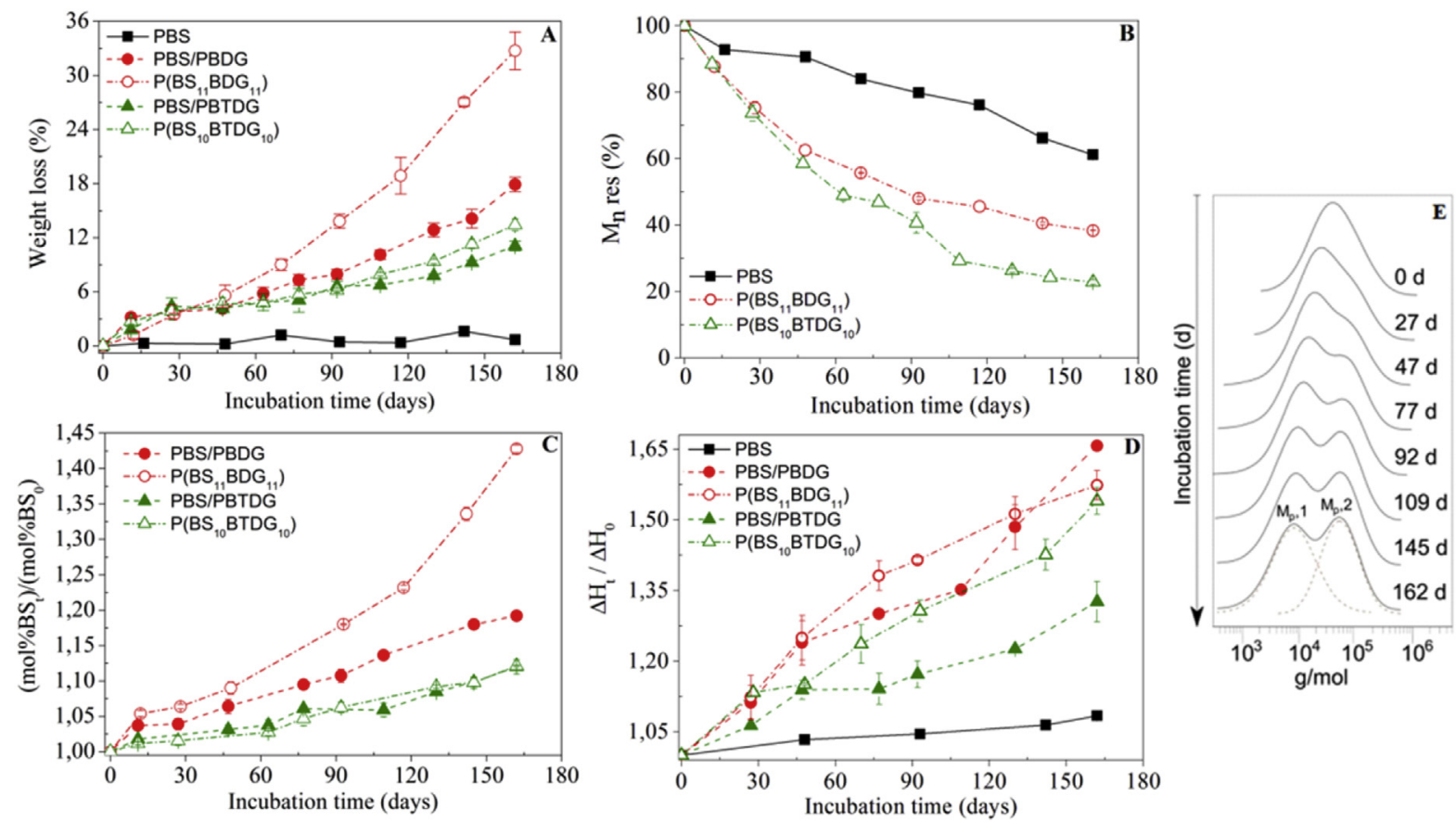

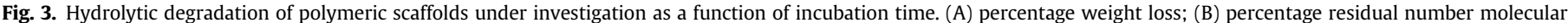
weight; (C) increase in BS mol\% content; (D) normalized heat of fusion; (E) GPC traces of PBS/PBDG blend as a function of incubation time.

content and a consequent decrease in the BDG and BTDG content was observed during degradation. The polymeric systems containing ether linkages (PBS/PBDG and $\mathrm{P}\left(\mathrm{BS}_{11} \mathrm{BDG}_{11}\right)$ ) underwent a significant change of molar composition, more evident in the blend compared to the copolymer. On the other hand, PBS/PBTDG and $\mathrm{P}\left(\mathrm{BS}_{10} \mathrm{BTDG}_{10}\right)$, underwent a similar decrease of BTDG content. By comparing weight loss (Fig. 3A) and chemical composition of the retrieved samples (Fig. 3C), it is evident that samples undergoing higher weight loss concomitantly displayed a higher increase of BS units. Therefore, the weight loss was mainly due to the solubilisation of either BDG or BTDG chain fragments since ester cleavage preferentially occurred on heteroatom-containing chain segments, which were easily solubilized in water due to their hydrophilic nature. Moreover, as expected, ether-oxygen-containing sequences demonstrated higher solubility in water with respect to sulphurcontaining ones: the lower decrease in molecular weight and the contemporary higher weight loss of $\mathrm{P}\left(\mathrm{BS}_{11} \mathrm{BDG}_{11}\right)$ with respect to $\mathrm{P}\left(\mathrm{BS}_{10} \mathrm{BTDG}_{10}\right)$, indicated that longer $\mathrm{BDG}$ sequences were solubilized in water generating a more pronounced change in BS mol\%.

A confirmation that the amorphous regions of a polymer degraded more quickly than the crystalline ones was obtained by analysing the degraded samples with DSC. All the calorimetric traces were found to be characterized by an endothermic peak associated with the fusion process of the crystalline portion of the material (similar to Fig. S1). The corresponding heat of fusion, at a certain time of degradation, was normalized to the heat of fusion of the corresponding non-degraded sample $\left(\Delta \mathrm{H}_{t} / \Delta \mathrm{H}_{0}\right)$. In all the polymeric compositions, the normalized heat of fusion regularly increased with incubation time, with the exception of PBS, whose crystallinity degree was not significantly affected (Fig. 3D). It is worth remembering that the increment of the crystalline/amorphous ratio can be also due to annealing, which occurs at a temperature comprised between $\mathrm{T}_{\mathrm{g}}$ and $\mathrm{T}_{\mathrm{m}}$ (i.e. $37^{\circ} \mathrm{C}$ in our case). The increase of $\Delta \mathrm{H}_{\mathrm{t}} / \Delta \mathrm{H}_{0}$ can, therefore, be considered as the sum of two contributions: (i) the higher degradation of the amorphous region with respect to crystalline one and (ii) annealing. In block copolymers, the annealing process plays a greater role than in the blends because of the lower crystallization rate of the former, as previously reported $[12,13]$. As a matter of fact, the crystallization process becomes more difficult as the BS block became shorter due to the effect of the second block (either BDG or BTDG), which limited the transport of the BS blocks on the crystal surface and acted as defect during chain folding. In this respect, the more pronounced increase in the heat of fusion of $\mathrm{P}\left(\mathrm{BS}_{10} \mathrm{BTDG}_{10}\right)$ compared to PBS/PBTDG is not surprising, although they showed a comparable weight loss (Fig. 3A). From a comparison between ether-oxygen-containing polymers and sulphur-containing ones, the higher increase in the heat of fusion of the former can be explained on the basis of their higher degradation rate.

\subsection{Seeding hMSCs on scaffolds}

To examine the performance of these new polyesters for skeletal tissue engineering, hMSCs were cultured on the samples for 28 days in $\mathrm{BM}, \mathrm{OM}, \mathrm{CM}$, or $\mathrm{MM}$. BM is a maintenance medium that does not trigger the osteogenic and chondrogenic differentiation of hMSCs, while CM is able to support the chondrogenic differentiation of hMSCs $[29,30]$. OM is a medium that supports the osteogenic differentiation of hMSCs and MM is a medium that also promotes the formation of a mineralized matrix [30,31]. The bioactivity of hMSCs was assessed by monitoring the GAG production, cellular morphology, cellular metabolism, ALP activity, and relative osteogenic and chondrogenic gene expressions. Polystyrene tissue culture plates were used as a positive control (data not shown). To investigate for a possible influence of fiber diameter, scaffolds of the same chemistry but different fiber diameter were assessed between $\mathrm{P}\left(\mathrm{BS}_{11} \mathrm{BDG}_{11}\right)-\mathrm{n}(430 \pm 260 \mathrm{~nm})$ and $\mathrm{P}\left(\mathrm{BS}_{11} \mathrm{BDG}_{11}\right)-\mathrm{m}(890 \pm 410 \mathrm{~nm})$. To analyze the effect of the introduction of a co-monomer (either BDG or BTDG) in the PBS chain, scaffolds of similar fiber dimension but different chemical group were examined among PBS, $\mathrm{P}\left(\mathrm{BS}_{10} \mathrm{BTDG}_{10}\right)$ and $\mathrm{P}\left(\mathrm{BS}_{11} \mathrm{BDG}_{11}\right)-\mathrm{n}$. To investigate the effect of reactive blending, PBS/ 
PBTDG and PBS/PBDG scaffolds were considered. Finally, to evaluate the effect of blending versus copolymerization, PBS/PBDG blend and $\mathrm{P}\left(\mathrm{BS}_{11} \mathrm{BDG}_{11}\right)-\mathrm{m}$, which had a comparable fiber dimension, were considered.

\subsection{Cell morphology and metabolic activity}

Cell attachment and morphology on scaffolds were examined by SEM (Fig. S2, Fig. S3 and Fig. S4). After 28 days culture, it could be seen that the hMSCs migrated, attached and proliferated on all types of scaffolds in all investigated media. No significant difference in cell morphology was observed between $\mathrm{P}\left(\mathrm{BS}_{11} \mathrm{BDG}_{11}\right)-\mathrm{n}$ and $\mathrm{P}\left(\mathrm{BS}_{11} \mathrm{BDG}_{11}\right)-\mathrm{m}$ in all media, indicating that the fiber dimension considered in the present work did not affect cell morphology. In OM, hMSCs on PBS/PBTDG and $\mathrm{P}\left(\mathrm{BS}_{10} \mathrm{BTDG}_{10}\right)$ had a more spread morphology compared to PBS/PBDG and $\mathrm{P}\left(\mathrm{BS}_{11} \mathrm{BDG}_{11}\right)-\mathrm{n}$ respectively, therefore revealing an effect of BTDG or BDG presence on cell morphology. However, in CM, hMSCs displayed a morphology with more bi-polar or multipolar extensions on PBS/PBTDG scaffolds in comparison with PBS/PBDG. In addition, no difference in cell morphology was observed between PBS/PBDG blend and its corresponding block copolymer of $\mathrm{P}\left(\mathrm{BS}_{11} \mathrm{BDG}_{11}\right)$ in all media.

Cell metabolic activity on seeded scaffolds was evaluated at days 7 and 28 using a Presto Blue assay (Fig. S5). Metabolic activity, which is indirectly related to cell viability, increased over the cell culture period in all media for all scaffolds. $\mathrm{P}\left(\mathrm{BS}_{11} \mathrm{BDG}_{11}\right)-\mathrm{n}$ and $\mathrm{P}\left(\mathrm{BS}_{11} \mathrm{BDG}_{11}\right)$ - $\mathrm{m}$ had a similar metabolic activity cultured in both $\mathrm{BM}$ and $\mathrm{CM}$ through the culture time points. In $\mathrm{OM}, \mathrm{P}\left(\mathrm{BS}_{11} \mathrm{BDG}_{11}\right)-\mathrm{n}$ showed a significantly higher metabolic activity at day 28 compared with $\mathrm{P}\left(\mathrm{BS}_{11} \mathrm{BDG}_{11}\right)$-m due to their difference in fiber dimension. PBS constructs displayed a slightly higher metabolic activity compared to $\mathrm{P}\left(\mathrm{BS}_{10} \mathrm{BTDG}_{10}\right)$ in both $\mathrm{BM}$ and $\mathrm{CM}$ at day 28 due to the presence of co-units of BTDG. Similarly, the presence of BDG blocks along polymer chain did not enhance the cell metabolism in comparison with PBS under the same conditions.
Interestingly, in the copolymers the introduction of BDG blocks generated a higher cell metabolism in CM compared to BTDG blocks, while in OM PBS/PBDG displayed higher cell metabolic activity compared to PBS/PBTDG.

\subsection{ALP activity}

To investigate early osteogenic differentiation of hMSCs cultured onto different scaffolds either in BM or in OM, we performed quantitative analysis of ALP at days 7 and 28 (Fig. 4A and B). ALP is commonly known as an early marker of osteogenic differentiation, which is involved in the formation of calcium phosphate crystals [32]. The ALP activity increased during cell culture in BM and OM and showed no remarkable difference between scaffolds at day 7 . After 28 days, $\mathrm{P}\left(\mathrm{BS}_{11} \mathrm{BDG}_{11}\right)$-m showed a similar ALP activity as $\mathrm{P}\left(\mathrm{BS}_{11} \mathrm{BDG}_{11}\right)-\mathrm{n}$ in OM. Shih et al. grew human hMSCs on electrospun type I collagen nanofibers [33]. They demonstrated that no significant difference of ALP activity of hMSCs after 12 days of culture in OM was observed between scaffolds with fiber diameter of 200-500 nm and fiber diameter of 500-1000 nm. PBS, $\mathrm{P}\left(\mathrm{BS}_{10} \mathrm{BTDG}_{10}\right)$ and $\mathrm{P}\left(\mathrm{BS}_{11} \mathrm{BDG}_{11}\right)$-n scaffolds supported a similar ALP activity in both BM and OM, which indicated that the presence of block units of BTDG and BDG do not elicit a specific effect on ALP activity. We also observed that ALP activity in both BM and OM was comparable for both PBS/PBTDG and PBS/PBDG. This suggested that the introduction of a second component of the blend, being either PBTDG or PBDG, has a similar effect on ALP activity. It is worth mentioning that the ALP activity on $\mathrm{P}\left(\mathrm{BS}_{11} \mathrm{BDG}_{11}\right)$ - $\mathrm{m}$ was higher than the corresponding blend in both investigated media.

The results of ALP activity were further confirmed by staining cells with ALP (Fig. S6 and S7). Low levels of ALP staining were present on all types of scaffolds at day 7 in both media without significant difference. $\mathrm{P}\left(\mathrm{BS}_{11} \mathrm{BDG}_{11}\right)$-n showed similar density in ALP staining during the cell culture period in all media compared to $\mathrm{P}\left(\mathrm{BS}_{11} \mathrm{BDG}_{11}\right)-\mathrm{m}$. At day 28 , the intensity of ALP staining remarkably
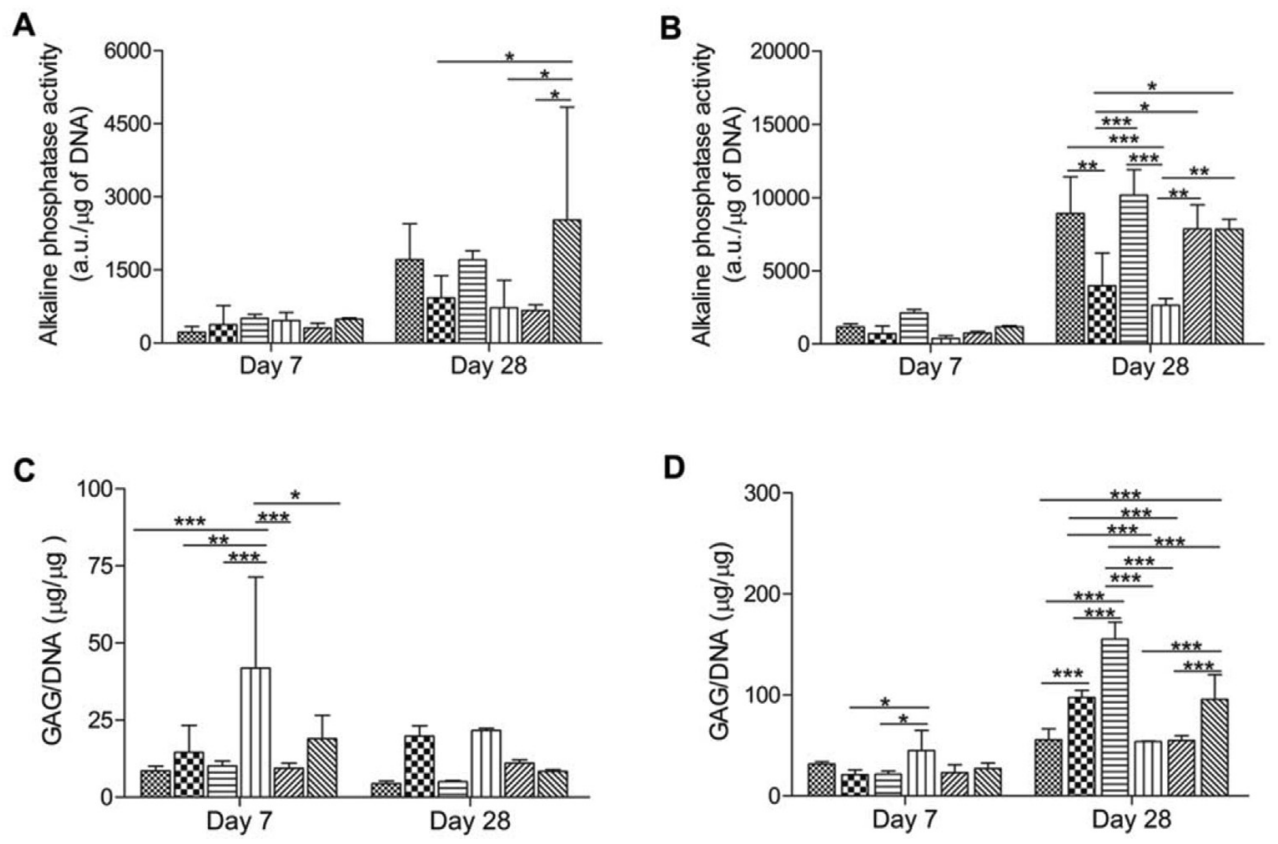

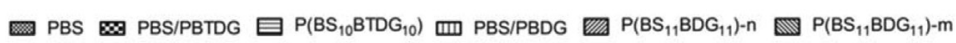

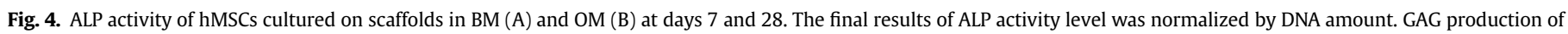
hMSCs cultured on scaffolds in BM (C) and CM (D) at day 7 and day $28 .{ }^{*} \mathrm{p}<0.05,{ }^{* *} \mathrm{p}<0.01,{ }^{* * *} \mathrm{p}<0.001$. 
increased on $\mathrm{PBS}$ and $\mathrm{P}\left(\mathrm{BS}_{10} \mathrm{BTDG}_{10}\right)$ scaffolds in $\mathrm{BM}$ compared to $\mathrm{P}\left(\mathrm{BS}_{11} \mathrm{BDG}_{11}\right)-\mathrm{n}$, suggesting a possible inductive effect on stem cell early osteogenic differentiation of these two chemical compositions. Furthermore, ALP staining increased in intensity on PBS, $\mathrm{P}\left(\mathrm{BS}_{10} \mathrm{TDG}_{10}\right)$, and $\mathrm{P}\left(\mathrm{BS}_{11} \mathrm{BDG}_{11}\right)$-n scaffolds in OM. Interestingly, PBS/PBDG and PBS/PBTDG scaffolds exhibited a constantly lower ALP activity at both time point in all media. In addition, $\mathrm{P}\left(\mathrm{BS}_{11} \mathrm{BDG}_{11}\right)$ - $\mathrm{m}$ showed a higher ALP staining in OM than the corresponding blend.

\subsection{GAG assay}

The quantification of GAG synthesis is shown in Fig. 4C and D. No significant differences were found between $\mathrm{P}\left(\mathrm{BS}_{11} \mathrm{BDG}_{11}\right)-\mathrm{m}$ and $\mathrm{P}\left(\mathrm{BS}_{11} \mathrm{BDG}_{11}\right)-\mathrm{n}$ in $\mathrm{BM}$. However, after 28 days, $\mathrm{P}\left(\mathrm{BS}_{11} \mathrm{BDG}_{11}\right)-\mathrm{m}$ had a significant higher $G A G$ deposition than $P\left(B_{11} B_{11} G_{11}\right)-n$ in $C M$, due to their difference in fiber dimension. This results is consistent with the findings by Bean et al. [34], who demonstrated that seeding hMSCs onto microfibers at a higher cell density promotes GAG production better than nanofibers. In $\mathrm{CM}$, at day $28, \mathrm{P}\left(\mathrm{BS}_{10} \mathrm{BTDG}_{10}\right)$ scaffold presented a significant increase in GAG production compared to PBS and $\mathrm{P}\left(\mathrm{BS}_{11} \mathrm{BDG}_{11}\right)-\mathrm{n}$. In addition, PBS/PBTDG displayed a significantly higher GAG amount than PBS/PBDG in CM. Both these results may indicate that the systems containing BTDG units may have a better effect on production of GAG in CM with respect to those containing BDG units. This result could be due to the presence of sulphur atoms along the polymer chain which are always observed in all of GAG [35]. $\mathrm{P}\left(\mathrm{BS}_{11} \mathrm{BDG}_{11}\right)$-m highlighted a lower GAG production than the corresponding blend in all media, which is in contrast to ALP activity. A recent study showed that hMSCs cultured on PCL electrospun scaffolds cultured for 4 weeks in chondrogenic medium had a GAG/DNA concentration of about $15 \mu \mathbf{g} / \mu \mathbf{g}$ [36]. Compared to this study, our scaffolds showed a higher GAG production at the same time point, However, in doing

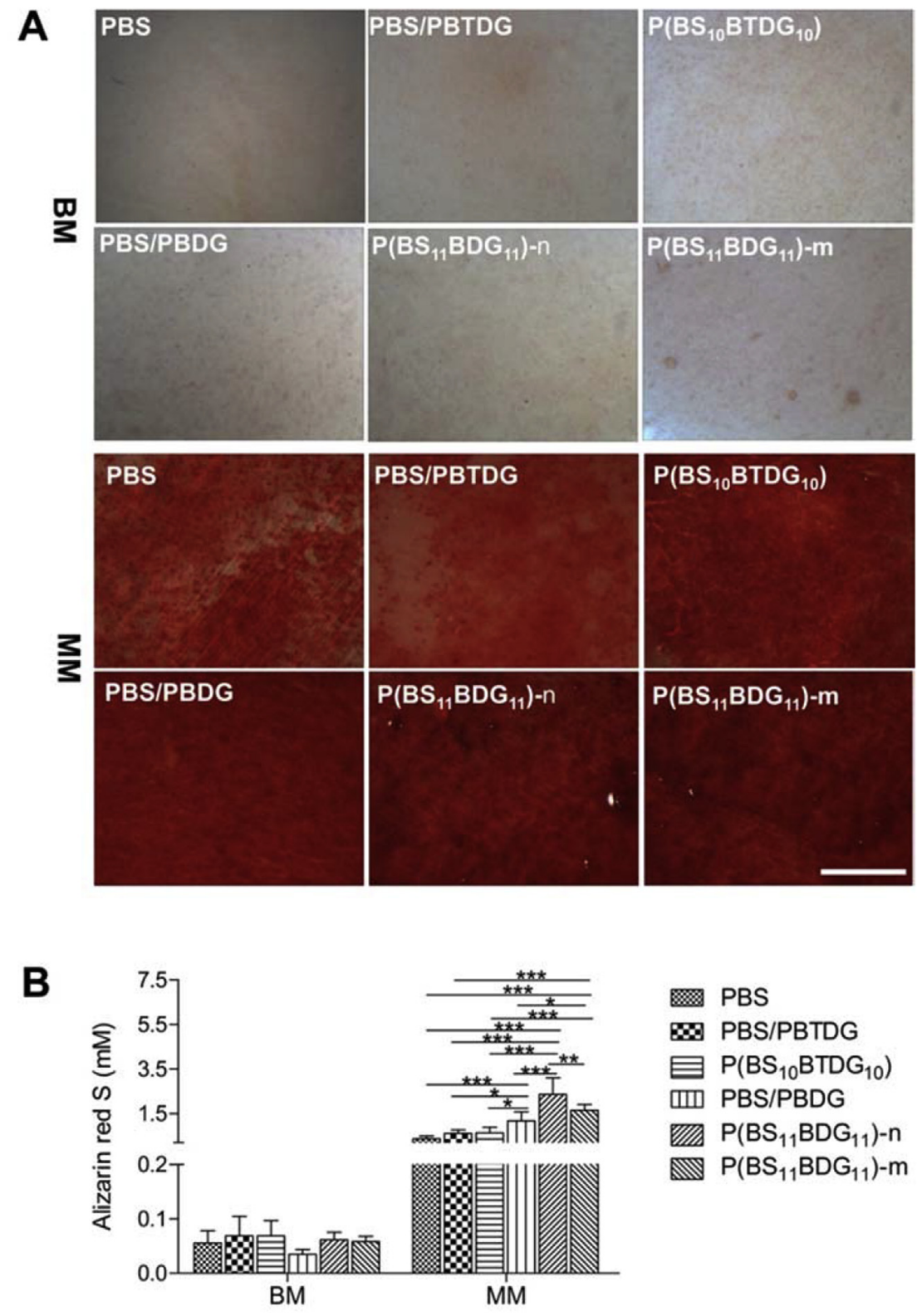

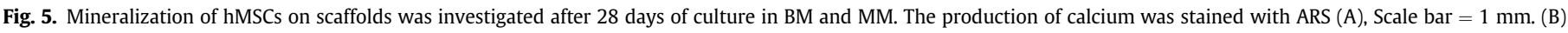
Quantification of the calcium deposition per scaffold by ARS assay at day $28 .{ }^{*} \mathrm{p}<0.05$. 
such comparison with other scaffolds used in the literature, we may still be limited by the potentially different cell donors and related intrinsic variability between patients.

\subsection{The mineralization of hMSCs}

ARS has been used to examine the level of calcium deposition after 28 days (Fig. 5). There were no apparently differences in ARS between scaffolds in BM. The intensity of ARS onto $\mathrm{P}\left(\mathrm{BS}_{11} \mathrm{BDG}_{11}\right)-\mathrm{n}$ scaffolds was higher than both $\mathrm{P}\left(\mathrm{BS}_{10} \mathrm{BTDG}_{10}\right)$ and PBS scaffolds and no significant differences were found between $\mathrm{P}\left(\mathrm{BS}_{10} \mathrm{BTDG}_{10}\right)$ and PBS in MM. These results suggested that the introduction of BDG blocks supported better mineralization when compared to the introduction of BTDG blocks. No appreciable differences in ARS were observed between PBS/PBTDG and PBS/PBDG, as well as between PBS/PBDG and $\mathrm{P}\left(\mathrm{BS}_{11} \mathrm{BDG}_{11}\right)$ - $\mathrm{m}$ for all media. Xuejun et al. determined the cell viability, growth and differentiation of hMSCs in PLGA (PLA:PGA ratio of 85:15) nanofibers [37]. They demonstrated that hMSCs treated with osteogenic medium showed positive staining to alizarin red after 4 weeks. The intensity of alizarin red staining was lower than that of our scaffolds. However, as explained earlier for chondrogenic studies, different cell donors were used, which should be taken into consideration when comparing our results with the literature.

\subsection{Osteogenic gene expression}

The investigation of osteoblast-related gene expression for hMSCs on scaffolds was performed at day 7 and day 28 (Fig. 6). In both media investigated, $\mathrm{P}\left(\mathrm{BS}_{11} \mathrm{BDG}_{11}\right)-\mathrm{n}$ and $\mathrm{P}\left(\mathrm{BS}_{11} \mathrm{BDG}_{11}\right)-\mathrm{m}$ showed a similar osteogenic gene expression including ALP, Runtrelated transcription factor 2(RUNX2), Collagen type I alpha 1 (COL1A1) and Bone sialoprotein (BSP), thus confirming that the difference in fiber dimension in the present work did not affect osteogenic differentiation. ALP expression for PBS, $\mathrm{P}\left(\mathrm{BS}_{10} \mathrm{TDG}_{10}\right)$ and $\mathrm{P}\left(\mathrm{BS}_{11} \mathrm{BDG}_{11}\right)$-n scaffolds were almost the same in BM. However, ALP expression on PBS was higher than on $\mathrm{P}\left(\mathrm{BS}_{11} \mathrm{BDG}_{11}\right)-\mathrm{n}$ scaffolds at day 28 in OM. RUNX2 strongly affects hMSCs osteogenic differentiation in the early stage, resulting in enhanced ALP, osteocalcin (OCN), osteopontin (OPN), and BSP expression [38]. The expression of RUNX2 on PBS was higher than that on $\mathrm{P}\left(\mathrm{BS}_{11} \mathrm{BDG}_{11}\right)$ $\mathrm{n}$ scaffolds at both time points in BM. $\mathrm{P}\left(\mathrm{BS}_{10} \mathrm{BTDG}_{10}\right)$ displayed a significant higher expression of RUNX2 at day 7 in BM in comparison with $\mathrm{P}\left(\mathrm{BS}_{11} \mathrm{BDG}_{11}\right)-\mathrm{n}$. COL1A1 is associated with the formation of the ECM, being considered essential for the development of an osteoblastic phenotype [39]. PBS showed a significant higher COL1A1 expression than $\mathrm{P}\left(\mathrm{BS}_{11} \mathrm{BDG}_{11}\right)$-n after 28 days in $\mathrm{BM}$, although no significant differences were found in OM. BSP, a late marker of hMSCs osteogenic differentiation, is a highly sulphated and glycosylated phosphoprotein in bone matrix [40]. BSP expression on PBS was significantly higher than that on $\mathrm{P}\left(\mathrm{BS}_{11} \mathrm{BDG}_{11}\right)-\mathrm{n}$ at day 28 in $\mathrm{OM}$. All gene expression tested did not highlight significant differences between PBS/PBDG and $\mathrm{P}\left(\mathrm{BS}_{11} \mathrm{BDG}_{11}\right)-\mathrm{m}$. These results suggest that PBS scaffolds may elicit a higher early osteogenic differentiation than copolymers containing BDG or BTDG units.

\subsection{Chondrogenic gene expression}

To know the potential of chondrogenic differentiation of hMSCs on the scaffolds under investigation, we evaluated a panel of chondrocyte-related genes: collagen type II alpha 1 (COL2A1), SOX9, aggrecan (ACAN) and activated leukocyte cell adhesion molecule (ALCAM) (Fig. 7). No significant difference in expression of the investigated gene profiles was observed between $\mathrm{P}\left(\mathrm{BS}_{11} \mathrm{BDG}_{11}\right)-n$ and $\mathrm{P}\left(\mathrm{BS}_{11} \mathrm{BDG}_{11}\right)-\mathrm{m}$ despite of their difference in fiber dimension. COL2A1 is a specific marker of hyaline cartilage ECM [41]. $\mathrm{P}\left(\mathrm{BS}_{11} \mathrm{BDG}_{11}\right)$ and $\mathrm{P}\left(\mathrm{BS}_{10} \mathrm{BTDG}_{10}\right)$ scaffolds displayed a higher expression of COL2A1 than PBS scaffolds at day 28 in BM. It could be inferred that the introduction of BTDG and BDG blocks along the PBS macromolecular chain was favourable for COL2A1 expression. The expression of COL2A1 on PBS/PBTDG scaffold was consistently higher than that on PBS/PBDG scaffolds, indicating that the blend containing BTDG units better supported COL2A1 expression compared to BDG units. SOX9, an early marker for chondrogenesis, is the transcriptional activator of COL2A1, COL9A1
ALP

$\mathrm{BM}$
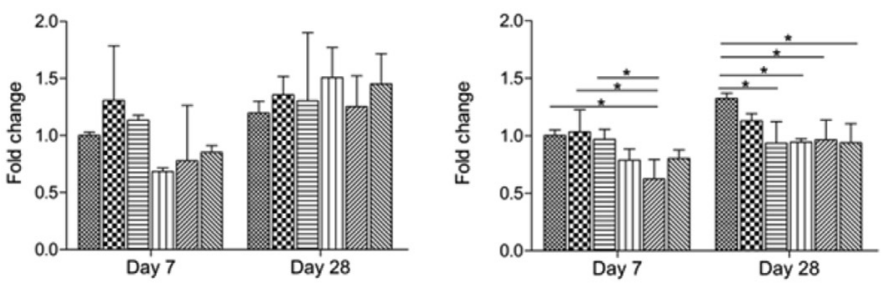

OM
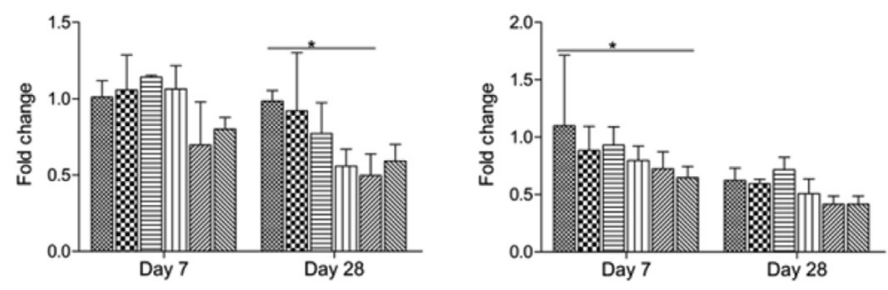

COL1A1
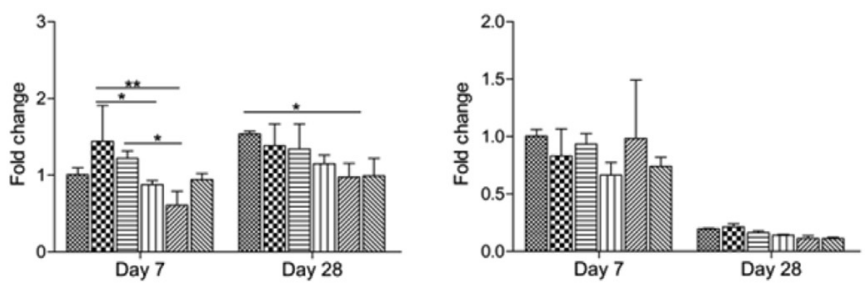

잠 $\mathbf{0}$

PBS/PBTDG $\equiv \mathrm{P}\left(\mathrm{BS}_{10} \mathrm{BTDG}_{10}\right)$
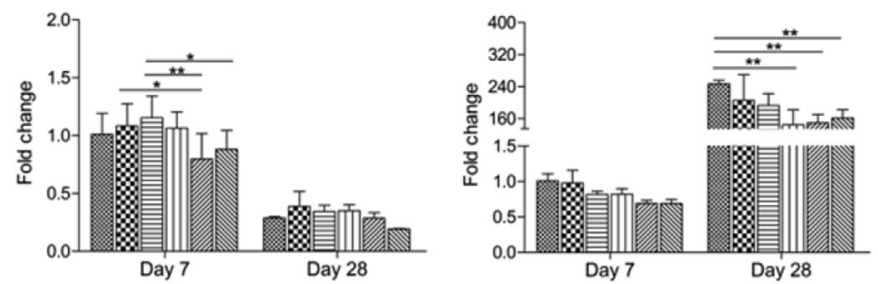

Fig. 6. Quantitative RT-PCR gene expression analysis of osteoblast-related genes in BM and OM at days 7 and 28 . ${ }^{*} \mathrm{p}<0.05$, ${ }^{* *} \mathrm{p}<0.01$. 

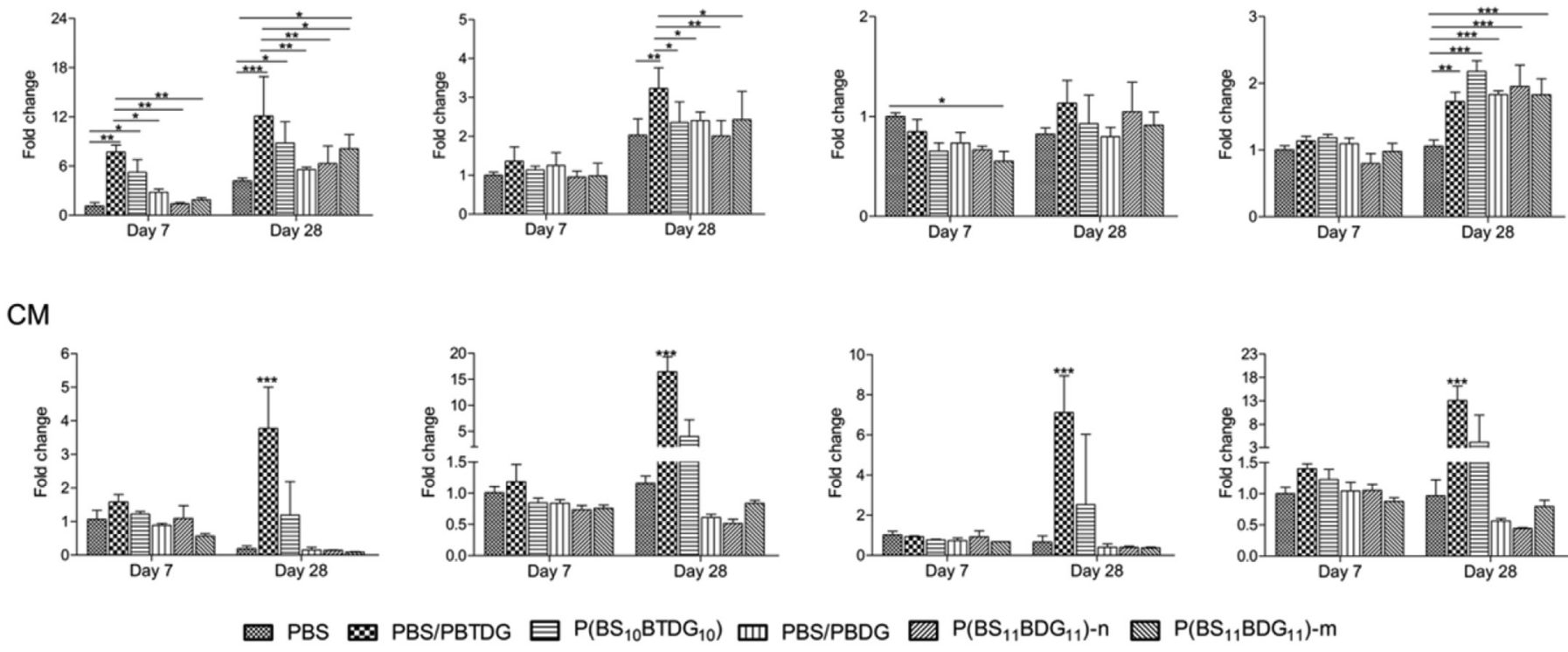

Fig. 7. Quantitative RT-PCR gene expression analysis of chondrogenisis-related genes in BM and CM at days 7 and 28 . ${ }^{*} \mathrm{p}<0.05$, ${ }^{* *} \mathrm{p}<0.01$, ${ }^{* * *} \mathrm{p}<0.001$.

and ACAN [42,43]. The expression of SOX9 was similar for all scaffolds at both time points in BM, while the expression of this gene significantly increased onto PBS/PBTDG scaffold at day 28 in CM. ALCAM is expressed on human articular chondrocytes and function as a marker for stemness [44]. At day 28, PBS/PBTDG scaffolds supported a significant higher expression of ALCAM in both $\mathrm{BM}$ and $\mathrm{CM}$ compared to PBS/PBDG scaffolds, thus suggesting that the blend containing BTDG units better supports ALCAM expression compared to BDG units. ACAN is one of the main proteoglycan in the articular cartilage matrix [45]. In BM, ACAN on $\mathrm{P}\left(\mathrm{BS}_{10} \mathrm{TDG}_{10}\right)$ scaffolds showed a significant up-regulation compared to PBS, due to the presence of BTDG units along the polymer chain. A significant higher expression of ACAN was observed on PBS/PBTDG scaffold compared to that on PBS/PBDG in both condition media at day 28 . Together, gene expressions results indicated that BTDG units displayed better support of hMSCs chondrogenesis with respect to BDG units. This result could be ascribed to the presence of sulphur atoms in the BTDG units. It is also worth noticing that PBS/PBTDG blends showed better performances than the corresponding block copolymer.

\section{Conclusions}

In the present study, PBS-based scaffolds from block copolymers containing heteroatoms have been successfully prepared by electrospinning. Hydrolytic degradation studies under physiological conditions showed that the hydrolysis rate can be tuned by acting on the kind of heteroatom introduced and on the molecular architecture, as these factors deeply influence both the crystallinity and the surface wettability of the investigated materials. The presence of BTDG units in the copolymers demonstrated a better support of chondrogenic differentiation of hMSCs compared to the presence of BDG units. Additionally, PBS scaffolds induced enhanced early osteogenic differentiation of hMSCs and the additional presence of ether units (BDG) resulted in enhanced mineralization. It is also worth mentioning that the same chemical composition, but a different molecular architecture (i.e. blend or block copolymer) highlighted a very different effect on hMSCs cell function such as differentiation. Therefore, molecular architecture revealed as an important parameter in terms of modulating the chemistry of the scaffolds. Taken together, these results demonstrated that the new copolymer family may therefore find applications for the regeneration of skeletal tissues in the regenerative medicine field. In the present work, we primarily focused on understanding cell-materials interactions in these new polymeric scaffolds, which is a fundamental required step in biomaterial science before continuing with more translational in vivo studies. In this respect, in vivo studies will be planned for future translational work.

\section{Acknowledgements}

H.C. thanks the China Council Scholarship programme for financial support (Grant \# 2011614016).

FP7 COST Action MP1206 "Electrospun Nano-fibres for bio inspired composite materials and innovative industrial applications" is acknowledged.

\section{Appendix A. Supplementary data}

Supplementary data related to this article can be found at http:// dx.doi.org/10.1016/j.biomaterials.2015.10.071.

\section{References}

[1] H. Chen, X. Fan, J. Xia, P. Chen, X. Zhou, J. Huang, et al., Electrospun chitosangraft-poly ( $\varepsilon$-caprolactone)/poly ( $\varepsilon$-caprolactone) nanofibrous scaffolds for retinal tissue engineering, Int. J. Nanomed. 6 (2011) 453.

[2] S. Agarwal, J.H. Wendorff, A. Greiner, Use of electrospinning technique for biomedical applications, Polymer 49 (2008) 5603-5621.

[3] B.D. Ulery, L.S. Nair, C.T. Laurencin, Biomedical applications of biodegradable polymers, J. Polym. Sci. Part B Polym. Phys. 49 (2011) 832-864.

[4] B.M. Holzapfel, J.C. Reichert, J.-T. Schantz, U. Gbureck, L. Rackwitz, U. Nöth, et al., How smart do biomaterials need to be? A translational science and clinical point of view, Adv. Drug Deliv. Rev. 65 (2013) 581-603.

[5] I. Bechthold, K. Bretz, S. Kabasci, R. Kopitzky, A. Springer, Succinic acid: a new platform chemical for biobased polymers from renewable resources, Chem. Eng. Technol. 31 (2008) 647-654.

[6] M. Gigli, M. Fabbri, N. Lotti, R. Gamberini, B. Rimini, A. Munari, Poly(butylene succinate)-based polyesters for biomedical applications: a review, Eur. Polym. 
J. (2015). Ref. No.: EUROPOL-D-15-00633.

[7] M. Soccio, N. Lotti, M. Gigli, L. Finelli, M. Gazzano, A. Munari, Reactive blending of poly (butylene succinate) and poly (triethylene succinate): characterization of the copolymers obtained, Polym. Int. 61 (2012) 1163-1169.

[8] G.C. Reilly, A.J. Engler, Intrinsic extracellular matrix properties regulate stem cell differentiation, J. Biomech. 43 (2010) 55-62.

[9] A.B. Faia-Torres, S. Guimond-Lischer, M. Rottmar, M. Charnley, T. Goren, K. Maniura-Weber, et al., Differential regulation of osteogenic differentiation of stem cells on surface roughness gradients, Biomaterials 35 (2014) 9023-9032.

[10] A. Higuchi, Q.-D. Ling, Y. Chang, S.-T. Hsu, A. Umezawa, Physical cues of biomaterials guide stem cell differentiation fate, Chem. Rev. 113 (2013) 3297-3328.

[11] M. Gigli, N. Lotti, M. Gazzano, L. Finelli, A. Munari, Macromolecular design of novel sulfur-containing copolyesters with promising mechanical properties, J. Appl. Polym. Sci. 126 (2012) 686-696.

[12] M. Gigli, N. Lotti, M. Gazzano, L. Finelli, A. Munari, Synthesis and characterization of novel poly (butylene succinate)-based copolyesters designed as potential candidates for soft tissue engineering, Polym. Eng. Sci. 53 (2013) 491-501.

[13] M. Soccio, N. Lotti, M. Gazzano, M. Govoni, E. Giordano, A. Munari, Molecular architecture and solid-state properties of novel biocompatible PBS-based copolyesters containing sulphur atoms, React. Funct. Polym. 72 (2012) 856-867.

[14] C. Gualandi, M. Soccio, M. Govoni, S. Valente, N. Lotti, A. Munari, et al., Poly (butylene/diethylene glycol succinate) multiblock copolyester as a candidate biomaterial for soft tissue engineering: Solid-state properties, degradability, and biocompatibility, J. Bioact. Compat. Polym. 27 (2012) 244-264.

[15] C. Gualandi, M. Soccio, E. Saino, M.L. Focarete, N. Lotti, A. Munari, et al., Easily synthesized novel biodegradable copolyesters with adjustable properties for biomedical applications, Soft Matter 8 (2012) 5466-5476.

[16] M. Gigli, M. Govoni, N. Lotti, E.D. Giordano, M. Gazzano, A. Munari, Biocompatible multiblock aliphatic polyesters containing ether-linkages: influence of molecular architecture on solid-state properties and hydrolysis rate, RSC Adv. 4 (2014) 32965-32976.

[17] M. Gigli, N. Lotti, M. Vercellino, L. Visai, A. Munari, Novel ether-linkages containing aliphatic copolyesters of poly (butylene 1, 4-cyclohexanedicarboxylate) as promising candidates for biomedical applications, Mater. Sci. Eng. C 34 (2014) 86-97.

[18] I. Sekiya, B.L. Larson, J.R. Smith, R. Pochampally, J.G. Cui, D.J. Prockop, Expansion of human adult stem cells from bone marrow stroma: conditions that maximize the yields of early progenitors and evaluate their quality, Stem Cells 20 (2002) 530-541.

[19] J.R. Smith, R. Pochampally, A. Perry, S.C. Hsu, D.J. Prockop, Isolation of a highly clonogenic and multipotential subfraction of adult stem cells from bone marrow stroma, Stem Cells 22 (2004) 823-831.

[20] A. Leferink, W. Hendrikson, J. Rouwkema, M. Karperien, vC. Blitterswijk, L. Moroni, Increased cell seeding efficiency in bioplotted three-dimensional PEOT/PBT scaffolds, J. Tissue Eng. Regen. Med. (2013 Nov 8.), http:// dx.doi.org/10.1002/term.1842.

[21] J. Zhang, X. Luo, D. Barbieri, A.M. Barradas, J.D. de Bruijn, C.A. Van Blitterswijk, et al., The size of surface microstructures as an osteogenic factor in calcium phosphate ceramics, Acta Biomater. 10 (2014) 3254-3263.

[22] C.A. Gregory, W.G. Gunn, A. Peister, D.J. Prockop, An Alizarin red-based assay of mineralization by adherent cells in culture: comparison with cetylpyridinium chloride extraction, Anal. Biochem. 329 (2004) 77-84.

[23] A.K. Gaharwar, S.M. Mihaila, A. Swami, A. Patel, S. Sant, R.L. Reis, et al., Bioactive silicate nanoplatelets for osteogenic differentiation of human mesenchymal stem cells, Adv. Mater. 25 (2013) 3329-3336.

[24] M. Gigli, A. Negroni, G. Zanaroli, N. Lotti, F. Fava, A. Munari, Environmentally friendly PBS-based copolyesters containing PEG-like subunit: effect of block length on solid-state properties and enzymatic degradation, React. Funct. Polym. 73 (2013) 764-771.

[25] M. Rizvi, P. Kumar, D. Katti, A. Pal, Mathematical model of mechanical behavior of micro/nanofibrous materials designed for extracellular matrix substitutes, Acta Biomater. 8 (2012) 4111-4122.

[26] X. Wei, Z. Xia, S.-C. Wong, A. Baji, Modelling of mechanical properties of electrospun nanofibre network, Int. J. Exp. Comput. Biomech. 1 (2009) 45-57.

[27] M. Gigli, A. Negroni, M. Soccio, G. Zanaroli, N. Lotti, F. Fava, et al., Influence o chemical and architectural modifications on the enzymatic hydrolysis of poly (butylene succinate), Green Chem. 14 (2012) 2885-2893.

[28] M. Mochizuki, M. Hirami, Structural effects on the biodegradation of aliphatic polyesters, Polym. Adv. Technol. 8 (1997) 203-209.

[29] A. Mentink, M. Hulsman, N. Groen, R. Licht, K.J. Dechering, J. van der Stok, et al., Predicting the therapeutic efficacy of MSC in bone tissue engineering using the molecular marker CADM1, Biomaterials 34 (2013) 4592-4601.

[30] A. Nandakumar, L. Yang, P. Habibovic, C. van Blitterswijk, Calcium phosphate coated electrospun fiber matrices as scaffolds for bone tissue engineering, Langmuir 26 (2009) 7380-7387.

[31] A. Nandakumar, A. Barradas, J. de Boer, L. Moroni, C. van Blitterswijk, P. Habibovic, Combining technologies to create bioactive hybrid scaffolds for bone tissue engineering, Biomatter 3 (2013).

[32] W. Liu, J. Lipner, J. Xie, C.N. Manning, S. Thomopoulos, Y. Xia, Nanofiber scaffolds with gradients in mineral content for spatial control of osteogenesis, ACS Appl. Mater. Interfaces 6 (2014) 2842-2849.

[33] Y.R.V. Shih, C.N. Chen, S.W. Tsai, Y.J. Wang, O.K. Lee, Growth of mesenchyma stem cells on electrospun type I collagen nanofibers, Stem Cells 24 (2006) 2391-2397.

[34] A.C. Bean, R.S. Tuan, Fiber diameter and seeding density influence chondrogenic differentiation of mesenchymal stem cells seeded on electrospun poly ( $\varepsilon$-caprolactone) scaffolds, Biomed. Mater. 10 (2015) 015018.

[35] B.C. Heng, T. Cao, E.H. Lee, Directing stem cell differentiation into the chondrogenic lineage in vitro, Stem Cells 22 (2004) 1152-1167.

[36] P.H. Ousema, F.T. Moutos, B.T. Estes, A.I. Caplan, D.P. Lennon, F. Guilak, et al., The inhibition by interleukin 1 of MSC chondrogenesis and the development of biomechanical properties in biomimetic 3D woven PCL scaffolds, Biomaterials 33 (2012) 8967-8974.

37] X. Xin, M. Hussain, J.J. Mao, Continuing differentiation of human mesenchyma stem cells and induced chondrogenic and osteogenic lineages in electrospun PLGA nanofiber scaffold, Biomaterials 28 (2007) 316-325.

[38] N.M. Teplyuk, M. Galindo, V.I. Teplyuk, J. Pratap, D.W. Young, D. Lapointe, et al., Runx2 regulates G protein-coupled signaling pathways to control growth of osteoblast progenitors, J. Biol. Chem. 283 (2008) 27585-27597.

[39] A. Polini, D. Pisignano, M. Parodi, R. Quarto, S. Scaglione, Osteoinduction of human mesenchymal stem cells by bioactive composite scaffolds without supplemental osteogenic growth factors, PLoS One 6 (2011) e26211.

[40] R. Franceschi, The developmental control of osteoblast-specific gene expression: role of specific transcription factors and the extracellular matrix environment, Crit. Rev, Oral Biol. Med. 10 (1999) 40-57.

[41] D. Fayol, G. Frasca, C. Le Visage, F. Gazeau, N. Luciani, C. Wilhelm, Use of magnetic forces to promote stem cell aggregation during differentiation, and cartilage tissue modeling, Adv. Mater. 25 (2013) 2611-2616.

[42] H. Akiyama, Control of chondrogenesis by the transcription factor Sox9, Mod Rheumatol. 18 (2008) 213-219.

[43] S.Q. Liu, Q. Tian, J.L. Hedrick, J.H.P. Hui, P.L.R. Ee, Y.Y. Yang, Biomimetic hydrogels for chondrogenic differentiation of human mesenchymal stem cells to neocartilage, Biomaterials 31 (2010) 7298-7307.

[44] G. Siegel, T. Kluba, U. Hermanutz-Klein, K. Bieback, H. Northoff, R. Schäfer, Phenotype, donor age and gender affect function of human bone marrowderived mesenchymal stromal cells, BMC Med. 11 (2013) 146.

[45] C. Kiani, C. Liwen, Y.J. WU, J.Y. Albert, B.Y. Burton, Structure and function of aggrecan, Cell Res. 12 (2002) 19-32. 